\title{
Netrin-3, a Mouse Homolog of Human NTN2L, Is Highly Expressed in Sensory Ganglia and Shows Differential Binding to Netrin Receptors
}

\author{
Hao Wang, ${ }^{1}$ Neal G. Copeland, ${ }^{2}$ Debra J. Gilbert, ${ }^{2}$ Nancy A. Jenkins, ${ }^{2}$ and Marc Tessier-Lavigne ${ }^{1}$ \\ ${ }^{1}$ Departments of Anatomy, and Biochemistry and Biophysics, Howard Hughes Medical Institute, University of California, \\ San Francisco, California 94143-0452, and 2Mammalian Genetics Laboratory, Advanced Bioscience Laboratories Basic \\ Research Program, Frederick Cancer Research and Development Center at the National Cancer Institute, Frederick, \\ Maryland 21702
}

The netrins comprise a small phylogenetically conserved family of guidance cues important for guiding particular axonal growth cones to their targets. Two netrin genes, netrin-1 and netrin-2, have been described in chicken, but in mouse so far a single netrin gene, an ortholog of chick netrin-1, has been reported. We report the identification of a second mouse netrin gene, which we name netrin-3. Netrin-3 does not appear to be the ortholog of chick netrin-2 but is the ortholog of a recently identified human netrin gene termed NTN2L ("netrin-2-like"), as evidenced by a high degree of sequence conservation and by chromosomal localization. Netrin-3 is expressed in sensory ganglia, mesenchymal cells, and muscles during the time of peripheral nerve development but is largely excluded from the CNS at early stages of its development. The murine netrin-3 protein binds to netrin receptors of the DCC (deleted in colorectal cancer) family [DCC and neogenin] and the UNC5 family (UNC5H1, UNC5H2 and UNC5H3). Unlike chick netrin-1, however, murine netrin-3 binds to DCC with lower affinity than to the other four receptors. Consistent with this finding, although murine netrin-3 can mimic the outgrowth-promoting activity of netrin-1 on commissural axons, it has lower specific activity than netrin-1. Thus, like netrin-1, netrin-3 may also function in axon guidance during development but may function predominantly in the development of the peripheral nervous system and may act primarily through netrin receptors other than DCC.

Key words: netrin-3; axon guidance; sensory neurons; mouse chromosome 17; peripheral nervous system; DCC
An early step in the development of the nervous system is the guidance of axonal growth cones to their correct targets. Significant progress has been made in recent years in identifying molecules that guide axons in a variety of organisms, including nematodes, insects, and vertebrates. These molecules include members of the cadherin and immunoglobulin superfamilies, ephrins, semaphorins, and netrins, all of which appear to have phylogenetically conserved functions (Tessier-Lavigne and Goodman, 1996).

The netrins play important roles in guiding various classes of axons in all of these species. In particular, genetic and embryologial studies have implicated netrins in attracting axons to the midline of the nervous systems of worms, flies, and vertebrates and in repelling other axons away from the midline, as well as in guiding other axons that do not navigate close to the midline (for review, see Tessier-Lavigne and Goodman, 1996; Culotti and Merz, 1998). The attractive effects of netrins appear to be mediated by receptors that are members of the DCC (deleted in colorectal cancer) subfamily of the immunoglobulin superfamily,

\footnotetext{
Received Jan. 7, 1999; revised April 2, 1999; accepted April 7, 1999.

This work was supported by a fellowship from the American Cancer Society to H.W. and a grant from the National Institutes of Health to M.T.L. M.T.L. is an Investigator of the Howard Hughes Medical Institute. N.G.C., D.J.G., and N.A.J. were supported by the National Cancer Institute, the Department of Health and Human Services, under contract with Advanced Bioscience Laboratories. We thank Drs. Yuan Zhang and Tim Kennedy for participating in initial experiments and Sasha Faynboym for technical assistance.

Correspondence should be addressed to Marc Tessier-Lavigne, Department of Anatomy, University of California, 513 Parnassus Avenue, Room S-1479, San Francisco, CA 94143-0452.

Copyright (C) 1999 Society for Neuroscience $\quad 0270-6474 / 99 / 194938-10 \$ 05.00 / 0$
}

which include the UNC-40 protein of Caenorhabditis elegans, the Frazzled protein of Drosophila, and the DCC and neogenin proteins of vertebrates (Chan et al., 1996; Keino-Masu et al., 1996; Kolodziej et al., 1996; Fazeli et al., 1997). In the case of repulsion, genetic data implicate the UNC-5 protein of C. elegans as a strong candidate receptor involved in mediating repulsive actions of the netrin UNC-6 (Hedgecock et al., 1990; LeungHagesteijn et al., 1992; Hamelin et al., 1993). In vertebrates, the UNC-5 homologs UNC5H1, UNC5H2, and UNC5H3 are all netrin-binding proteins, consistent with the possibility that they too function as repulsive netrin receptors (Ackerman et al., 1997; Leonardo et al., 1997).

Within each species, netrins appear to be a small family. One netrin, the UNC-6 gene product, has been described in the nematode C. elegans, and two in Drosophila (Netrin-A and Netrin-B) (Ishii et al., 1992; Harris et al., 1996; Mitchell et al., 1996). In vertebrates, biochemical purification led to the identification of chick netrin-1 and netrin-2 (Serafini et al., 1994). Orthologs of chick netrin-1 have been identified in other vertebrate species, including mouse (Serafini et al., 1996), Xenopus (de la Torre et al., 1997), zebrafish (Lauderdale et al., 1997; Strahle et al., 1997), and human (Meyerhardt et al., 1999). A netrin gene named NTN2L ("netrin-2-like") (van Raay et al., 1997) has been reported in human as well; it does not appear to be the strict ortholog of either chick netrin-1 or chick netrin-2.

Here, we describe the cloning, expression, binding properties, and in vitro activities of a novel murine netrin, netrin-3, which is the ortholog of human NTN2L. Two properties of netrin-3 distinguish it from previously reported vertebrate netrins: its exclu- 
Mouse netrin-2 Human netrin-2 Chick netrin-2 Chick netrin-1

Mouse netrin-2 Human netrin-2 Chick netrin-2 Chick netrin-1

Mouse netrin-2 Human netrin-2 Chick netrin-2 Chick netrin-1

Mouse netrin-2 Human netrin-2 Chick netrin-2 Chick netrin-1

Mouse netrin-2 Human netrin-2 Chick netrin-2 Chick netrin-1

Mouse netrin-2 Human netrin-2 Chick netrin-2 Chick netrin-1

Mouse netrin-2 Human netrin-2 Chick netrin-2 Chick netrin-1

Mouse netrin-2 Human netrin-2 Chick netrin-2 Chick netrin-1

\section{Mouse netrin-2 Human netrin-2 Chick netrin-2 Chick netrin-1}

Mouse netrin-2 Human netrin-2 Chick netrin-2 Chick netrin-1

Mouse netrin-2 Human netrin-2 Chick netrin-2 Chick netrin-1
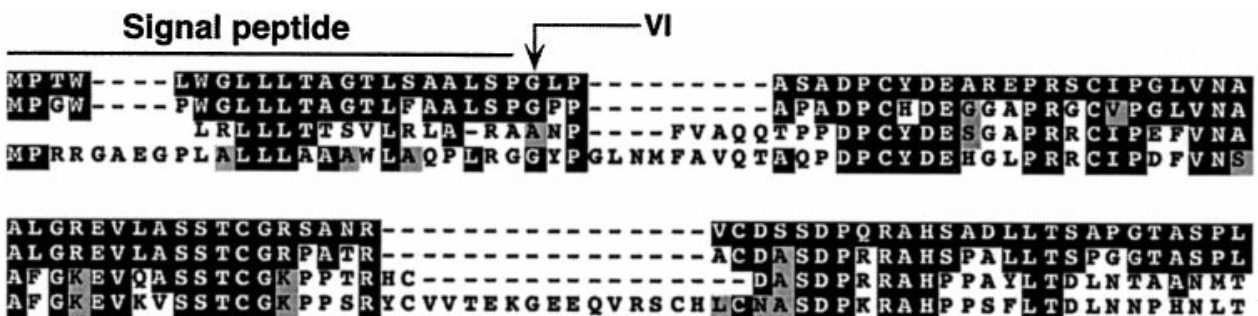

CDSSD PQRAHS ADLLTSAPGTASPL

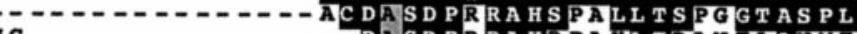

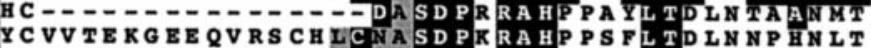

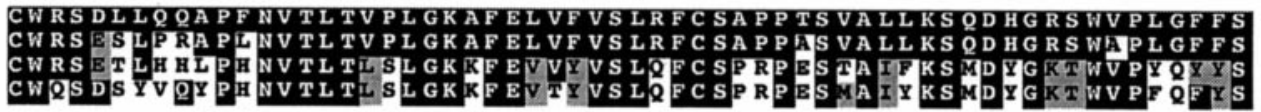

151

151

150
180

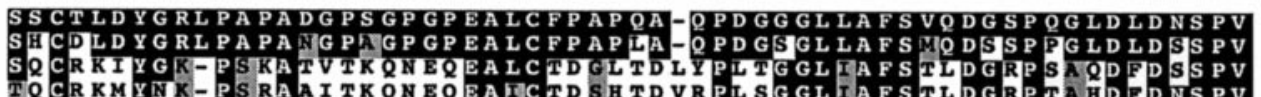

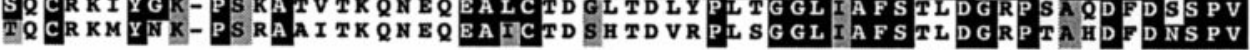

210
210

209

VI

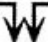

V-1

LQDWVTAT DIRTVLTR PAT- - - - - QGDTR DGGVTVPYSYSATELQVGGRCKCNGHAS LQDWVTAT DVRVVLTR PST LQDWVTAT DIRVVFSR PHLFREIGGREA GEEDGGKG ATPY YY SVGELOVG GR CK CNGHAS LQDWVTATDIKVTFSREHTFG-- - DENEDDSELARDSYFYAVSDLQVGGRCKCNGHAS $\mathrm{V}-1 \frac{\mathrm{s}}{\mathrm{v}-2}$

RCLLDTHGHLVCDCQHGTEGPDCSRCKPFYCDRP WQRATGQEAHACLACSCNGHARRCRF RCLLDT QG HL ICDCRHGTEGPDCGRCKPFYCDRPWQRATARESHACLACSCNGHARRCRF RC VIJPEQKL VCDCKH NTEGPECDRCKPFHYDRPWQRASAREANECLACNCNIHARRCRF RCVRDRDDNLVCDCKHNTAGPECDRCKPFH DRPWQRATAREANECVACNCNEHARRCRF $\mathrm{V}-2$

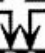
$\mathrm{V}-3$ NMELYRLSGRRSGGVCSNCRHITAGRHCHYCREGFYRDPGRVLSDRRACRACDCHPVGAA NMELYRLSGRRSGGVCLNCRHNTAGRHCHYCREGFYRDPGRALSDRRACRACDCHPVGAA NMELYKLS GRKSGGVCLNCRHNTAGRHCHYCKEGFYRDISKS ITDRKACKACDCHPVGAA $\mathrm{V}-3$

C

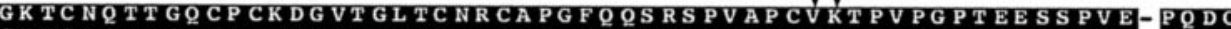
GKTCNOTTGQCPCKDGVTGLTCNRCAPGFOOSRSPVAPCVKT PIPGPTEDSS PVE-PQDC

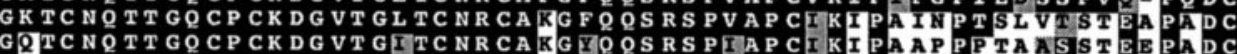
239

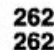

262

294 294

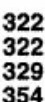

329
354

382

382
389

389
414

441
441

449

474

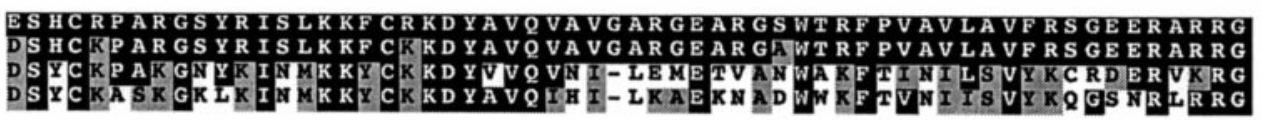

$\mathbf{5 0 1}$
$\mathbf{5 0 1}$
$\mathbf{5 0 8}$
$\mathbf{5 3 3}$

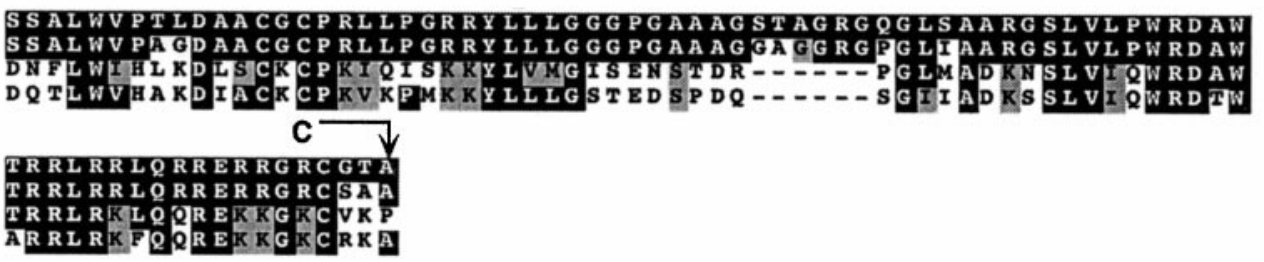

Figure 1. Alignment of the predicted amino acid sequences of murine netrin-3, human NTN2L, chick netrin-2, and chick netrin-1 proteins. Amino acid residues identical among other netrins and murine netrin-3 are shaded in black. Similar residues are shaded in gray. The different domains of mouse netrin-3 (domains $V I, V-1, V-2, V-3$, and $C$ ) are indicated as defined by homology with other netrins (Serafini et al., 1994; Harris et al., 1996; Mitchell et al., 1996; de la Torre et al., 1997). The nucleotide sequence of mouse netrin-3 has been submitted to GenBank.

sion from the CNS at early stages of development and its selectivity in binding to various netrin receptors. These results suggest that netrin-3 may be more specialized for development of the peripheral nervous system and for functioning through a subset of known netrin receptors.

\section{MATERIALS AND METHODS}

Isolation of a murine netrin-3 $c D N A$. Two million phage plaques from a neonatal mouse brain cDNA library (Stratagene, La Jolla, CA) were screened with a ${ }^{32} \mathrm{P}$-labeled murine netrin-1 cDNA. Filters (Hybond-N; Amersham, Arlington Heights, IL) were hybridized at $42^{\circ} \mathrm{C}$ in $0.4 \mathrm{M}$ NaPO4, pH 7.2, $1 \%$ BSA, 1 mm EDTA, $7 \%$ SDS, $15 \%$ formamide, 250 $\mu \mathrm{g} / \mathrm{ml} \mathrm{salmon}$ sperm DNA, and $2 \times 10^{6} \mathrm{cpm} / \mathrm{ml}$ of the probe for $16 \mathrm{hr}$. The filters were washed repeatedly at $55^{\circ} \mathrm{C}$ in $0.2 \times \mathrm{SSC}$ and $0.1 \%$ SDS and autoradiographed. Three positive clones were isolated and excised into the phagemid vector pBluscript as directed by the manufacturer (Stratagene).

To isolate the $5^{\prime}$ end of the cDNA, two rounds of $5^{\prime}$ rapid amplification of cDNA ends (RACE) (Boehringer Mannheim, Indianapolis, IN) were conducted according to the manufacturer's instructions. Two micrograms of poly $\left(\mathrm{A}^{+}\right)$RNA from mouse embryonic day 12.5 (E12.5) embryos were reverse transcribed using a $3^{\prime}$ primer complementary to the sequence $5^{\prime}$ GGCACGAGCCCGTGCTCCAA3' contained in the $5^{\prime}$ end of the available cDNA sequence. A poly $\left(\mathrm{A}^{+}\right)$tail was then added using terminal transferase. The cDNA was used as template to amplify the $5^{\prime}$ end, and a $0.5 \mathrm{~kb}$ PCR product was cloned into the pCRII vector (Invitrogen, San Diego, CA). Because this fragment still did not contain the entire open reading frame, a second round of $5^{\prime} \mathrm{RACE}$ was conducted using a primer complementary to 5'CCGCAGCGGGCTACTCTGCAGAC3', a sequence in the $5^{\prime}$ end of the newly cloned fragment. This second round of RACE resulted in the cloning of a $0.3 \mathrm{~kb}$ sequence, which contains the 
$5^{\prime}$ end of the gene, including the putative ATG and $150 \mathrm{bp}$ of 5'UTR. The continuity of these PCR products with the existing cDNA clone was confirmed by sequence comparison with the genomic DNA.

Isolation of genomic DNA. One pair of primers (5'ATCTTGGCACTGCAGACCCGGCACG3' and 5'GTCCGAGGAATCGCAGACGC-

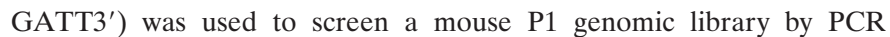
(Genome Systems, Inc., St. Louis, MO). Two positive clones containing an $80 \mathrm{~kb}$ insert were mapped, and the genomic DNA spanning the cDNA region was subcloned into pBluscript $\mathrm{SK}(-)$.

Interspecific mouse backcross. Interspecific backcross progeny were generated by mating (C57BL/6J $\times$ Mus spretus) $\mathrm{F} 1$ females and C57BL/6J males as described previously (Copeland and Jenkins, 1991). A total of $205 \mathrm{~N} 2$ mice were used to map the NtN3 locus. DNA isolation, restriction enzyme digestion, agarose gel electrophoresis, Southern blot transfer, and hybridization were performed essentially as described previously (Jenkins et al., 1982). All blots were prepared with Hybond-N ${ }^{+}$

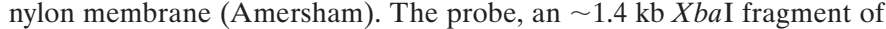
mouse genomic DNA from the $5^{\prime}$ UTR, was labeled with $\left[\alpha^{32} \mathrm{P}\right] \mathrm{dCTP}$ using a nick translation labeling kit (Boehringer Mannheim); washing was done to a final stringency of $1.0 \times \mathrm{SSCP}$ and $0.1 \% \mathrm{SDS}$ at $65^{\circ} \mathrm{C}$. A fragment of $4.8 \mathrm{~kb}$ was detected in $S c a$ I digested C57BL/6J DNA, and a fragment of $3.1 \mathrm{~kb}$ was detected in a ScaI digested M. spretus-specific fragment followed in backcross mice.

A description of the probes and restriction fragment length polymorphisms (RFLPs) for the loci linked to Ntn3, including Masl, E4fl, and Piml, has been reported previously (Rooney et al., 1998). Recombination distances were calculated using Map Manager, version 2.6.5. Gene order was determined by minimizing the number of recombination events required to explain the allele distribution patterns.

Expression of mouse netrin-3 protein and netrin-3(VI.V)-Fc in 293 EBNA cells. The genomic sequences encoding the signal peptide, domain VI and domain $\mathrm{V}$, do not contain introns as revealed by sequence comparison to cDNA clones and $5^{\prime}$ RACE products. Therefore, this region of the genomic DNA was fused with the cDNA and cloned into the mammalian expression vector pCEP4 (Invitrogen). In addition, a sequence encoding the myc epitope was also cloned in frame $5^{\prime}$ to the stop codon to generate a plasmid we named $\mathrm{pMN} 3^{\mathrm{myc}}$. For netrin-3 (VI.V)Fc, human Fc DNA was fused in frame to generate netrin-3 (VI.V)-Fc. Transfection of pMN3 ${ }^{\text {myc }}$ and netrin-3 (VI.V)-Fc into 293 EBNA cells was performed using LipofectAMINE (Life Technologies, Gaithersburg, MD) as directed by the manufacturer. Transfected cells were selected with G418 $(250 \mu \mathrm{g} / \mathrm{ml})$ and hygromycin B $(40 \mu \mathrm{g} / \mathrm{ml})$. After $7 \mathrm{~d}$, the resistant cell colonies were pooled, expanded, and frozen as a stable source of transfected cells.

Purification of murine netrin-3 from transfected cells. Recombinant murine netrin- 3 protein was purified from conditioned media by heparin affinity chromatography to $75-85 \%$ homogeneity, as assessed by silver staining. Netrin-3 (VI.V)-Fc protein was purified from conditioned media by protein-A affinity chromatography (Harlow and Lane, 1988) to greater than $90 \%$ homogeneity.

Northern blot analysis. Total RNA from various stages of embryos and brains was extracted (Chomczynski and Sacchi, 1987). Poly $\left(\mathrm{A}^{+}\right)$RNA was isolated by oligo-dT cellulose (Sambrook et al., 1989). For Northern analysis, $3 \mu \mathrm{g}$ of poly $\left(\mathrm{A}^{+}\right)$RNA was used. The blotted membrane was hybridized with ${ }^{32} \mathrm{P}$-labeled cDNA in $0.32 \mathrm{M} \mathrm{NaPO} 4, \mathrm{pH} 7.2,7 \%$ SDS, 1 mM EDTA, $1 \%$ BSA, and $250 \mu \mathrm{g} / \mathrm{ml}$ salmon sperm DNA at $65^{\circ} \mathrm{C}$ for 16 $\mathrm{hr}$. The membrane was washed repeatedly in $0.1 \times$ SSC and $1 \%$ SDS at $65^{\circ} \mathrm{C}$ and exposed to $\mathrm{x}$-ray film at $-80^{\circ} \mathrm{C}$ in the presence of an intensifying screen for $3 \mathrm{~d}$.

In situ hybridization. Embryos from different stages were fixed in $4 \%$ paraformaldehyde in PBS, cryoprotected in $30 \%$ sucrose in PBS, embedded in O.C.T. compound, and cryostat sectioned at $16 \mu \mathrm{m}$ thickness. Antisense and sense RNA probes for in situ hybridization were transcribed from linearized plasmid using T7 or T3 RNA polymerase in the presence of $\left[{ }^{35} \mathrm{~S}\right] \mathrm{UTP}$. For murine netrin-3, a 1287 base probe spanning 1037 bases in the coding region and 250 bases in the 3'UTR was used. Another 368 base probe corresponding to 118 bases in the coding region and 250 bases in the $3^{\prime}$ UTR gave similar patterns as the 1037 base probe (data not shown). We routinely used the 1037 base probe for murine netrin-3 in situ hybridization. The murine netrin-1 and chick netrin-1 probes were the same as described previously (Kennedy et al., 1994; Serafini et al., 1996). For chick netrin-2, a 1243 base probe spanning 205 bases in the coding region and 1038 bases in the 3'UTR was used. For each cDNA, a sense probe was also synthesized and showed no signal under the same conditions as for the antisense probe. Sections were
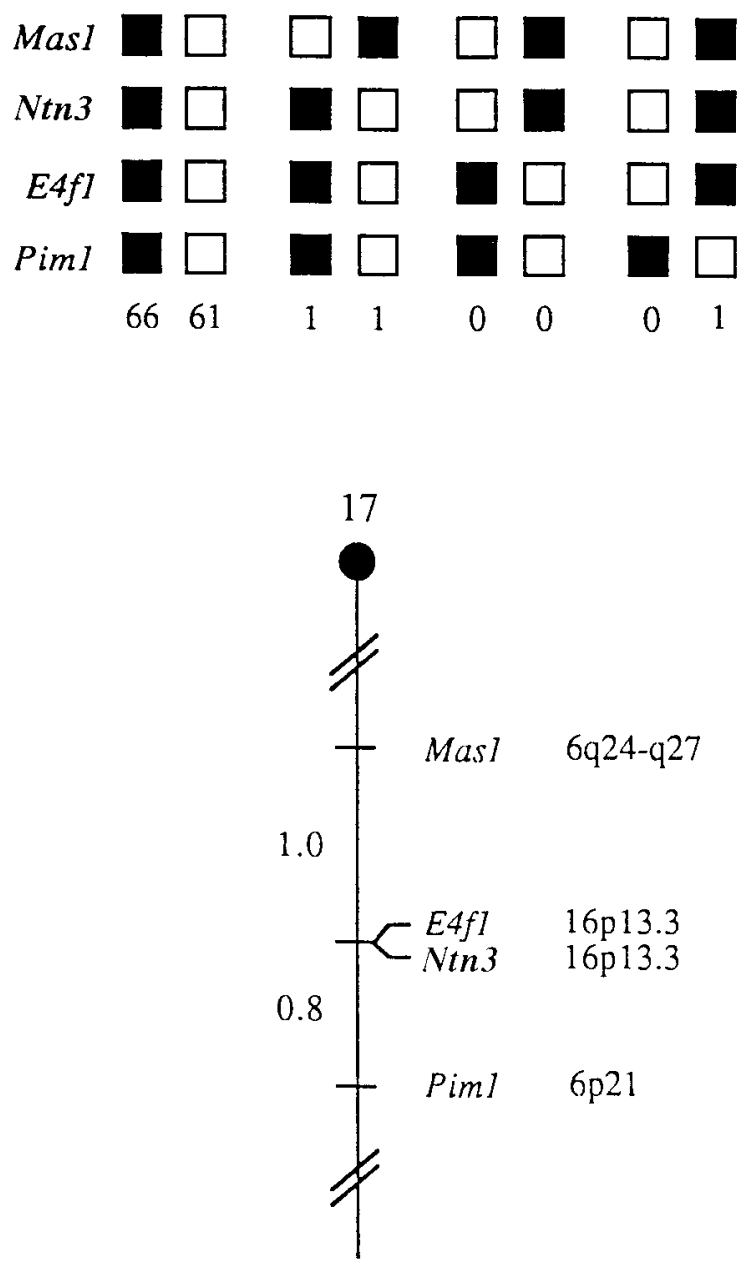

Figure 2. Ntn3 maps in the proximal region of mouse chromosome 17. Ntn 3 was placed on chromosome 17 by interspecific backcross analysis. The segregation patterns of Ntn3 and flanking genes in 130 backcross animals that were typed for all loci are shown at the top. For individual pairs of loci, $>130$ animals were typed (see Materials and Methods). Each column represents the chromosome identified in the backcross progeny that was inherited from the $(\mathrm{C} 57 \mathrm{BL} / 6 \mathrm{~J} \times M$. spretus $) \mathrm{F} 1$ parent. The black boxes represent the presence of a $\mathrm{C} 57 \mathrm{BL} / 6 \mathrm{~J}$ allele, and the white boxes represent the presence of a $M$. spretus allele. The number of offspring inheriting each type of chromosomes is listed at the bottom of each column. A partial chromosome 17 linkage map showing the location of $N t n 3$ in relation to linked genes is shown at the bottom. Recombination distances between loci in centimorgans are shown to the left of the chromosome, and the position of the loci in human chromosomes, where known, are shown to the right. References for the human map position of loci cited in this study can be obtained from Genome Data Base, a computerized database of human linkage information maintained by The William H. Welch Medical Library of the Johns Hopkins University (Baltimore, MD).

processed, hybridized, and washed at high stringency as described previously (Wang et al., 1994). Slides were coated with photographic emulsion (K5; Polysciences, Warrington, PA), developed after 3-7 d, stained with hemotoxylin, dehydrated and cleared with xylene, and mounted in Permount (Fisher Scientific, Houston, TX).

Explant culture. E13 rat dorsal explant cultures with the cell aggregates were as described previously (Kennedy et al., 1994; Serafini et al., 1994), with micrographs of explants taken $16 \mathrm{hr}$ after the onset of incubation of the cultures. Chemorepulsive activity was assayed as described previously (Colamarino and Tessier-Lavigne, 1995), with explants fixed $40 \mathrm{hr}$ after the onset of incubation of the cultures and trochlear motor axons stained with the F84.1 antibody.

Binding experiments. Transient transfections of expression constructs 
encoding rat DCC, rat neogenin, rat UNC5H1, rat UNC5H2, mouse UNC5H3, and rat L1 were performed using LipofectAMINE (Life Technologies). Forty-eight hours after transfection, the cells were incubated with $2 \mu \mathrm{g} / \mathrm{ml}$ purified murine netrin-3 protein in PBS supplemented with $1 \%$ goat serum, $2 \mu \mathrm{g} / \mathrm{ml}$ heparin, and $0.05 \%$ sodium azide at $37^{\circ} \mathrm{C}$ for $1 \mathrm{hr}$. After washing three times with PBS, the cells were fixed with $4 \%$ paraformaldehyde at room temperature for $10 \mathrm{~min}$. The cells were then stained using monoclonal antibody $9 \mathrm{E} 10$, followed by a $\mathrm{Cy}$ 3-conjugated Goat anti-mouse IgG secondary antibody.

Equilibrium binding on $293 \mathrm{~T}$ cells transiently expressing these receptors was quantified essentially as described previously (Keino-Masu et al., 1996; Leonardo et al., 1997). Briefly, the transfected cells were plated on a poly-D-lysine-coated 48 -well plate. After washing with PBS containing $1 \%$ BSA and $0.05 \%$ sodium azide, followed by incubation with the ligand in binding buffer (PBS plus 1\% BSA plus $0.05 \%$ sodium azide plus 2 $\mu \mathrm{g} / \mathrm{ml}$ heparin) for $3 \mathrm{hr}$ on ice, the cells were washed twice with binding buffer. The cells were then fixed with $50 \%$ methanol, $100 \%$ methanol, and $4 \%$ paraformaldehyde sequentially. Fixed cells were washed three times before incubation with $\left[{ }^{125} \mathrm{I}\right]$ goat anti human $\operatorname{IgG}(1 \mu \mathrm{Ci} / \mathrm{ml}$ in $10 \%$ heat-inactivated goat serum) for $30 \mathrm{~min}$ at room temperature. The activity was counted after washing with PBS three times, followed by dissolving the cells in $1 \mathrm{M} \mathrm{NaOH}$ and $1 \%$ Triton X-100. Experiments were performed in triplicate for each concentration.

\section{RESULTS}

\section{Cloning of the murine netrin-3 gene}

To search for other murine netrin homologs, we screened a neonatal mouse brain cDNA library with a mouse netrin-1 probe. Three positive clones were isolated and sequenced. The documented netrins have a characteristic structure, comprising three domains called VI, V, and C. Domains VI and V are so named because of their homology to domains VI (a globular domain) and $\mathrm{V}$ (comprising epidermal growth factor-like repeats) of the laminin $\gamma$ chains. The $\mathrm{C}$-terminal domain $\mathrm{C}$ is highly basic. The sequence of each of the clones we obtained in our screen contained an open reading frame homologous to domains $\mathrm{V}$ and $\mathrm{C}$ of murine netrin-1. All three clones lacked sequences corresponding to domain VI and the signal peptide. The $5^{\prime}$ end of the existing clones was obtained by two rounds of $5^{\prime} \mathrm{RACE}$, yielding regions homologous to domain VI and the signal peptide. We later confirmed the continuity of these fragments with the cDNA clones by Northern analysis and by comparison to genomic sequence (data not shown).

The predicted amino acid sequence of the murine netrin-3 protein shows homology to all other known netrins (Fig. 1), including a high degree of homology at the amino acid level to the human NTN2L gene product (87.2\% identity) and a lower level of homology to chick netrin-2 (71.6\%) and chick netrin-1 $(52.4 \%)$. Therefore, murine netrin-3 is likely the strict ortholog of human NTN2L. However, the homology between mouse netrin-3 and chick netrin-2 is much lower, indicating that netrin-3 is likely not the strict ortholog of chick netrin-2, as previously noted also for NTN2L (van Raay et al., 1997).

\section{Chromosomal localization of the murine netrin-3 gene}

The chromosomal location of murine netrin-3 (Ntn3) was determined by interspecific backcross analysis using progeny derived from matings of $[(\mathrm{C} 57 \mathrm{BL} / 6 \mathrm{~J} \times$ M. spretus $) \mathrm{F} 1 \times \mathrm{C} 57 \mathrm{BL} / 6 \mathrm{~J}]$ mice. This interspecific backcross mapping panel has been typed for over 2400 loci that are well distributed among all the autosomes, as well as the $\mathrm{X}$ chromosome (Copeland and Jenkins, 1991). C57BL/6J and M. spretus DNA was digested with several enzymes and analyzed by Southern blot hybridization for informative RFLPs using a murine Ntn3 probe. The $3.1 \mathrm{~kb}$ ScaI M. spretus RFLP (see Materials and Methods) was used to follow the segregation of the murine netrin-3 locus in backcross mice. The mapping results indicated that murine netrin-3 is located in the proximal region of mouse chromosome 17 linked to Masl, E4fl, and Piml. Although 130 mice were analyzed for every marker and are shown in the segregation analysis (Fig. 2), up to 192 mice were typed for some pairs of markers. Each locus was analyzed in pairwise combinations for recombination frequencies using additional data. The ratios of the total number of mice exhibiting recombinant chromosomes to the total number of mice analyzed for each pair of loci and the most likely gene order are as follows: Centromere-Masl-2/192-Ntn30/160-E4fl-1/132-Piml. The recombination frequencies [expressed as genetic distances in centimorgans $(\mathrm{cM})$ plus the SE] are as follows: Masl-1.0 $\pm 0.7-[N t n 3$, E4fl] $-0.8 \pm 0.8$-Piml. No recombinants were detected between Ntn3 and $E 4 f l$ in 160 animals typed in common, suggesting that the two loci are within $1.9 \mathrm{cM}$ of each other (upper $95 \%$ confidence limit).

Furthermore, we have compared the interspecific map of chromosome 17 with a composite mouse linkage map that reports the map location of many uncloned mouse mutations (provided from the Mouse Genome Database, maintained at The Jackson Laboratory, Bar Harber, ME). Ntn3 mapped in a region of the composite map that contains the t-complex, a $\sim 12 \mathrm{cM}$ interval that contains numerous mutations, including those affecting tail length, male sterility, transmission ratio distortion, and prenatal lethality (Green, 1989). Whether mutations in Ntn3 result in any of the t-complex phenotypes remains to be determined.

The proximal region of mouse chromosome 17 shares regions of homology with human chromosome 6 and 16 (Fig. 2). The placement of Ntn3 in this interval in mouse is consistent with the human localization of NTN2L, 16p13.3 (van Raay et al., 1997).

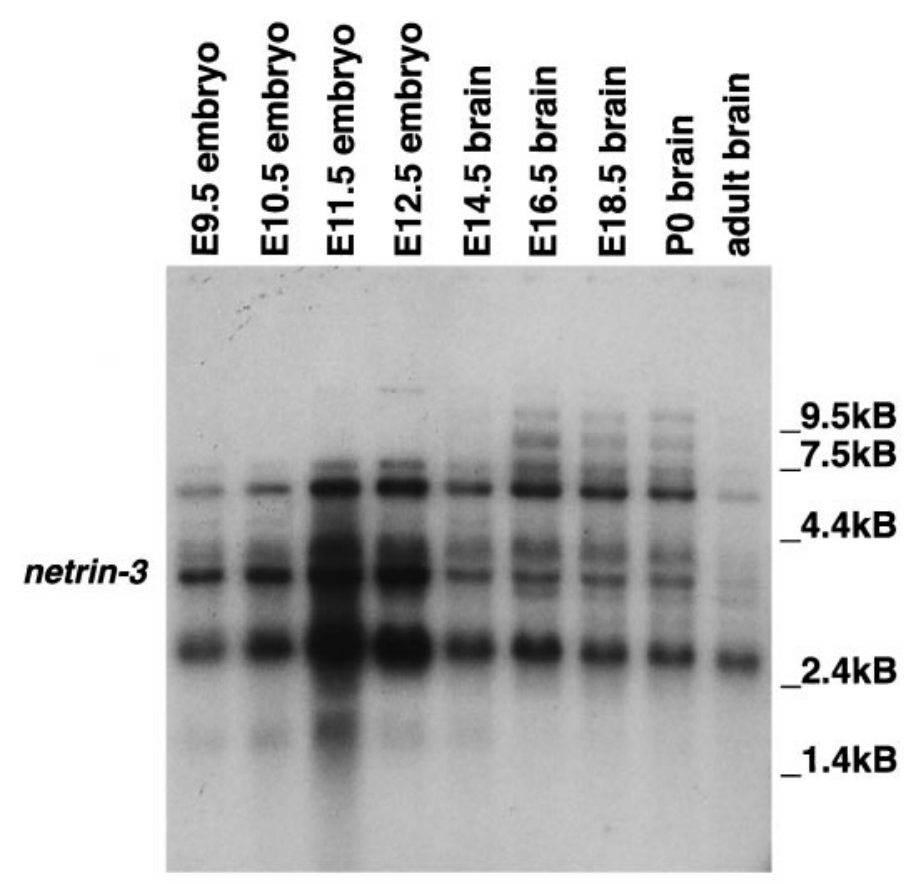

EF1a

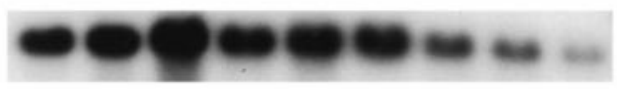

Figure 3. Northern analysis of murine netrin-3 expression in mRNA extracted from E9.5, E10.5, E11.5, and E12.5 whole embryos and E14.5, $\mathrm{E} 16.5$, and E18.5 neonatal and adult brain. The position of RNA molecular weight markers on the gel is indicated on the right. Elongation factor 1 a $(E F 1 a)$ was used as a control for loading of mRNA. 
Murine netrin-1

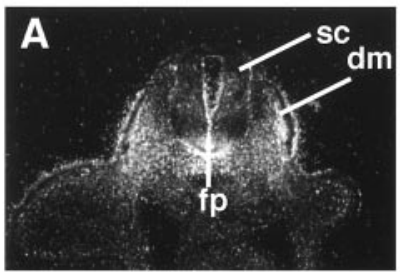

E9.5
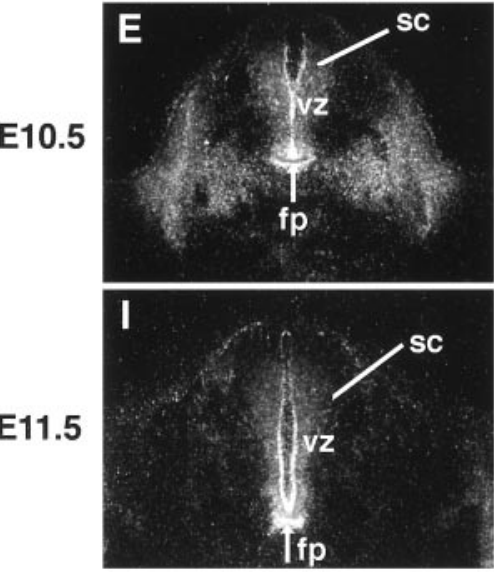

Murine netrin-3
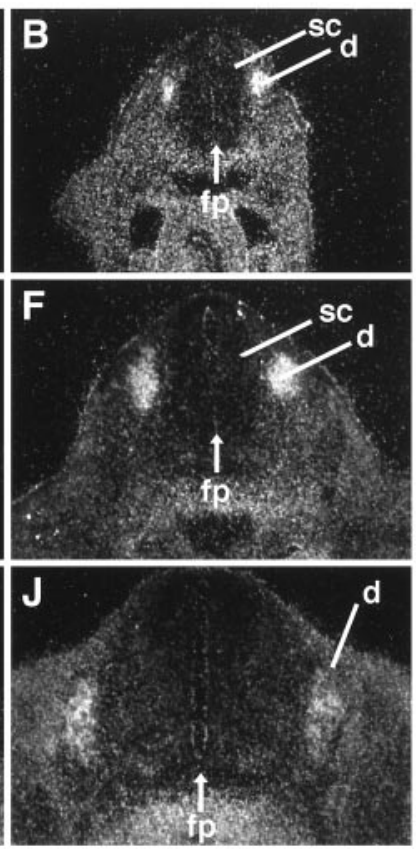

Chicken netrin-1
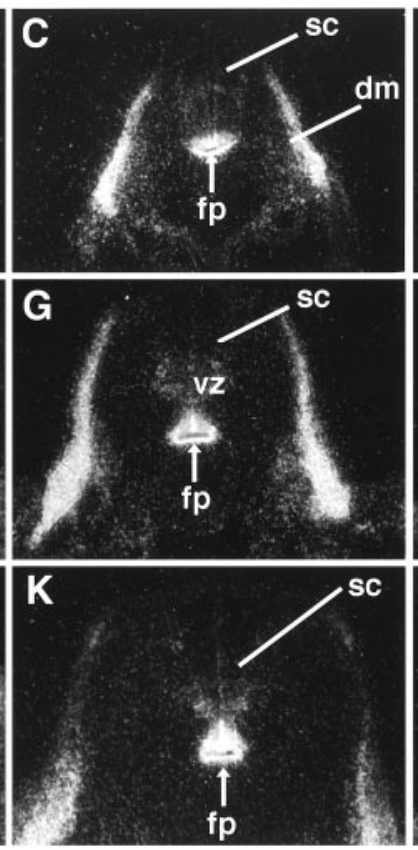

Chicken netrin-2
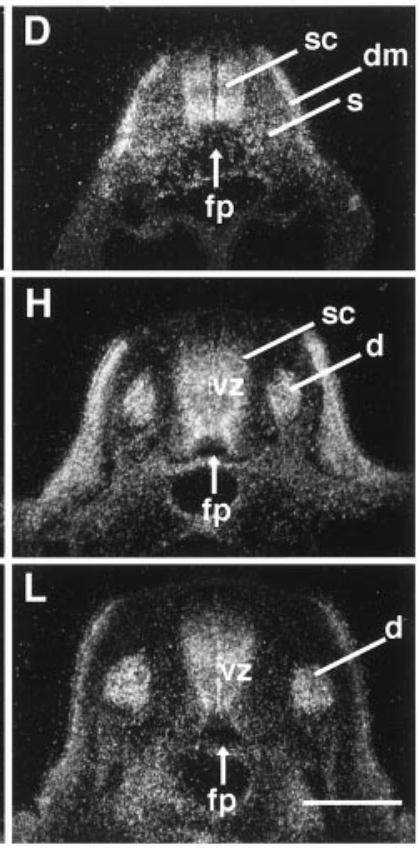

St18

St22

St26

Figure 4. Comparison of expression of murine netrin-1 $(A, E, I)$, murine netrin-3 $(B, F, J)$, chick netrin-1 $(C, G, K)$, and chick netrin-2 $(D, H, L)$ in the spinal cord by in situ hybridization. Comparable developmental stages in mouse and chick are illustrated: $A-D$, E9.5 in mouse $(A, B)$ and stage 18 in chick $(C, D) ; E-H$, E10.5 in mouse $(E, F)$ and stage 22 in chick $(G, H) ; I-L$, E11.5 in mouse $(I, J)$ and stage 26 in chick $(K, L)$. (Note that the signal along the edge of the ventricular zone and in the central canal in $I$ and $J$ represents an edge effect and not a real signal). sc, Spinal cord; $d$, dorsal root ganglion; $f p$, floor plate; $v z$, ventricular zone; $d m$, dermomyotome; $s$, somite. Scale bar, $0.25 \mathrm{~mm}$.

\section{Sites of expression of murine netrin-3}

Northern analysis shows that several transcripts are made from the murine netrin-3 gene (Fig. 3). The major transcripts are 6.5, 4.0 , and $3.0 \mathrm{~kb}$, respectively. In mRNA derived from whole embryos during early stages of nervous system development, the expression of murine netrin-3 is highest at approximately E12.5. Expression in brain tissue was also detected from E14.5 (the earliest stage examined) into adulthood (Fig. 3). In adult brain, the $3.0 \mathrm{~kb}$ transcript predominates.

To determine the regional distribution of murine netrin-3 transcripts at early embryonic stages and whether, like netrin-1, it could play a role in axon guidance, we performed in situ hybridization analysis of murine netrin-3 expression on sections of E9.5-E14.5 mouse embryos. In contrast to the two chicken netrin genes and murine netrin-1, murine netrin-3 is not detected at early stages of spinal cord development (E9.5 and E10.5 in the mouse) (Fig. $4 A-H$ ). Instead, the highest signal is detected in the dorsal root ganglia (Fig. 4B,F). At E11.5, murine netrin-3 mRNA is also detected at low levels in the motor column in the ventral spinal cord (Fig. $4 J$ ). At all these developmental stages, no signal was detected in the floor plate or in the ventricular zone, two sites of expression of the chick netrin-1, chick netrin-2, and mouse netrin-1 genes. The murine netrin-3 signal in the ventral spinal cord is maintained at a low level through E14.5 (Figs. 5B,C, 6D).

At E9.5, the expression of netrin-3 visualized on transverse sections at the forelimb level was highest in condensing dorsal root ganglia (Fig. 4A). This expression in the dorsal root ganglia persists through E12.5 (Fig. $5 A-C$ ) but then reduces in intensity by E14.5 (Fig. $5 D$ ). We also observed expression in mesenchymal tissues. At E9.5 and E10.5, low diff use signals were seen in the mesenchyme (Fig. 5A). At E11.5 and E12.5, this signal is mostly localized in the condensing mesenchyme (Fig. 5B,C). At E14.5, the expression of netrin-3 was found in the differentiating myotubes (Fig. $5 D-F$ ). The expression of murine netrin- 1 was also examined at E14.5 and compared with that of murine netrin-3. Interestingly, at this later stage of development, with the exception of the spinal cord, murine netrin-3 and murine netrin-1 have very similar expression patterns, especially in the muscles and in the bronchi of the lung (Fig. 5G-I), indicating that the two genes may have similar or redundant functions in these tissues at this stage of development.

In the head region, expression at E9.5 is highest in the differentiating trigeminal (V) ganglion, the geniculate (VII) ganglion, the vestibular (VIII) ganglion, the glossopharyngeal (IX) ganglion, and the nodose and jugular (X) ganglia (Fig. $6 \mathrm{~A}$ and data not shown). This expression persists through E12.5 (Fig. 6) and is reduced by E14.5 (data not shown). At E11.5 and E12.5, the murine netrin-3 gene is also expressed in the developing thalamus (Fig. $6 C, D$ ). In addition, a lower level of expression was also observed in mesenchymal tissues at all these stages. At later stages (after E16.5), expression of netrin-3 is still observed in many regions of the brain but at moderate or low levels and very diffusely (data not shown).

\section{Murine netrin-3 binds to known netrin receptors}

To help elucidate the possible function of murine netrin-3, we examined whether the netrin-3 protein binds to known netrin receptors. Murine netrin-3 protein was expressed with a C-terminal c-myc epitope tag in 293 EBNA cells (see Materials and Methods). The expression of the protein was confirmed by Western analysis using monoclonal antibody 9E10, which recognizes the myc epitope (data not shown). Netrin-3 protein was 

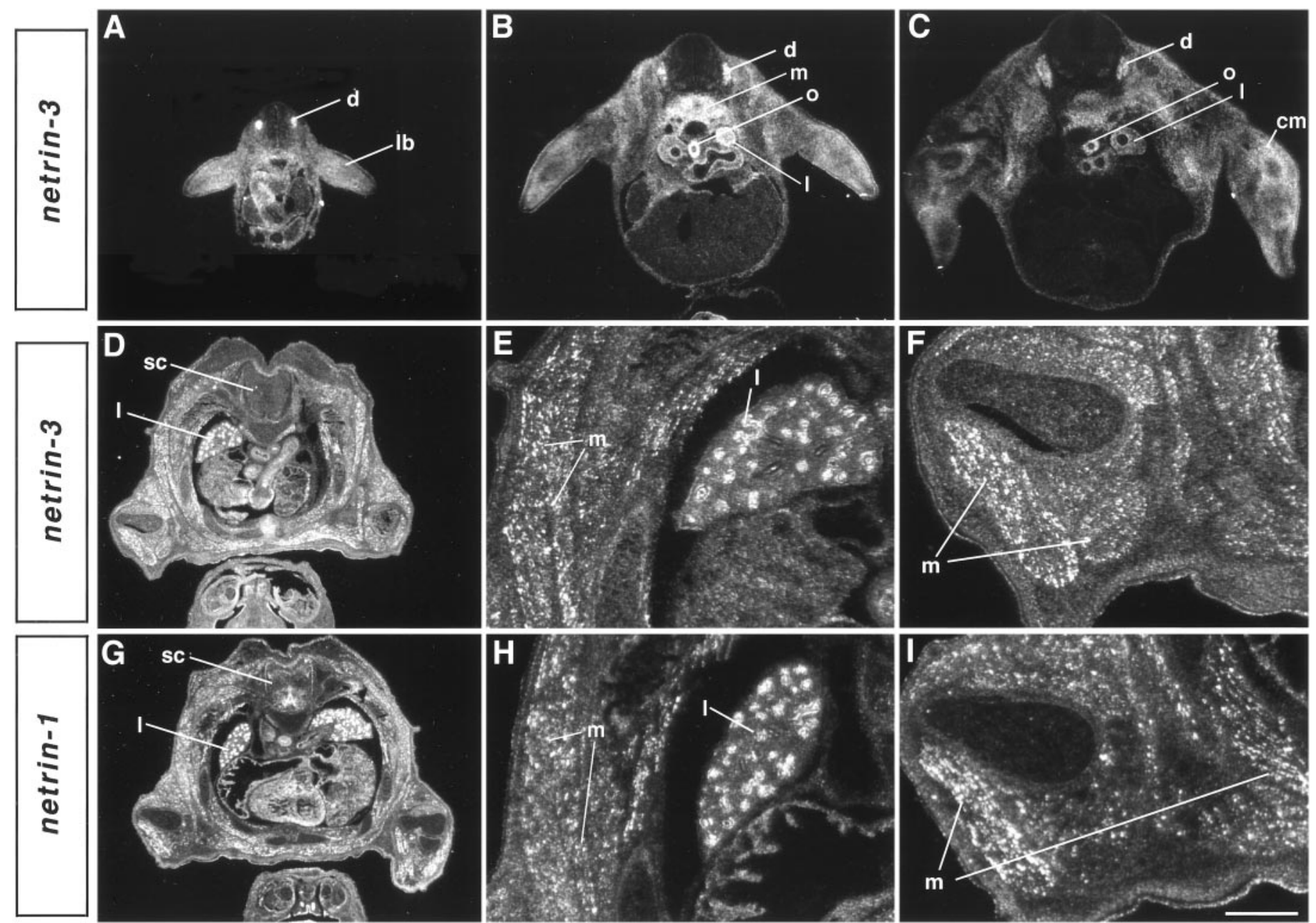

Figure 5. Expression of murine netrin-3 and murine netrin-1 at different stages at the forelimb level. $A-C$, Murine netrin-3 at E10.5 $(A)$, E11.5 (B), and E12.5 $(C) . D-F$, Expression of murine netrin-3 at E14.5 in transverse sections $(D)$, with higher magnification showing expression in the lung $(E)$ and in the muscles $(E, F)$. $G-I$, Expression of murine netrin-1 at E14.5 in sections adjacent to those in $D-F$, respectively. Note that the expression patterns of netrin-1 and netrin-3 are similar in muscles and the lung. $d$, Dorsal root ganglion; $l b$, limb bud; $o$, oesophagus; $c m$, condensing mesenchyme; $m$, muscle; $l$, lung; sc, spinal cord. Scale bar: $A-D, G, 1.4 \mathrm{~mm} ; E, F, H, I, 0.33 \mathrm{~mm}$.

purified and used in binding assays (see Materials and Methods). Netrin-3 was found to bind all the receptors to which netrin-1 binds, including DCC, neogenin, UNC5H1, UNC5H2, and UNC5H3 (Fig. 7), suggesting that netrin-3 may function through these receptors.

The affinity of the receptors for murine netrin-3 was estimated in equilibrium binding experiments using netrin-3(VI.V)-Fc, a fusion of the N-terminal two-thirds of netrin-3 to the constant portion of human IgG. A similar fusion of chick netrin-1 to Fc, the netrin-1(VI.V)-Fc protein, has been used to estimate the affinity of the receptors for netrin-1. This netrin-1 derivative is bioactive but, unlike full-length netrin-1, it does not aggregate at high concentrations, thereby improving the reliability of binding estimates (Keino-Masu et al., 1996; Leonardo et al., 1997). Specific binding of netrin-3(VI.V)-Fc to each of the receptors showed saturation, and binding curves were fitted to the Hill equation, yielding $K_{\mathrm{d}}$ values of $11.5,3.0,6.2,3.3$, and $4.5 \mathrm{~nm}$ for DCC, neogenin, UNC5H1, UNC5H2, and UNC5H3, respectively (Fig. 8 ). These values are comparable with those observed for the binding of netrin-1(VI.V)-Fc to its receptors (Keino-Masu et al., 1996; Leonardo et al., 1997), with the exception of the affinity for DCC, which is four times lower for netrin-3(VI.V)-Fc than for
netrin-1(VI.V)-Fc. We were not able to perform binding experiments with full-length netrin-3 because it also aggregates at high concentrations, particularly those necessary to evaluate binding to DCC. However, it seems reasonable to make use of the estimates obtained using netrin-3(VI.V)-Fc because the (VI.V)-Fc construct has been shown to be a reliable indicator of binding interactions in the case of netrin-1 (Keino-Masu et al., 1996).

\section{Murine netrin-3 has outgrowth-promoting activity for spinal commissural axons and chemorepulsive activity for trochlear motor axons}

Given that netrin-3 and netrin-1 bind to the same receptors, we examined further whether murine netrin-3 can mimic the previously documented activities of chick netrin-1 in vitro. We therefore first tested whether cells expressing murine netrin-3 or purified murine netrin-3 protein can also elicit commissural axon outgrow th from E13 dorsal explants, an activity that in the case of netrin-1 requires the function of the DCC receptor (Keino-Masu et al., 1996). Aggregates of transfected cells secreting recombinant murine netrin-3 always elicited directional axon outgrowth $(n>20)$ (Fig. 9B), whereas purified murine netrin-3 protein always elicited radial axon outgrowth from spinal cord explants 

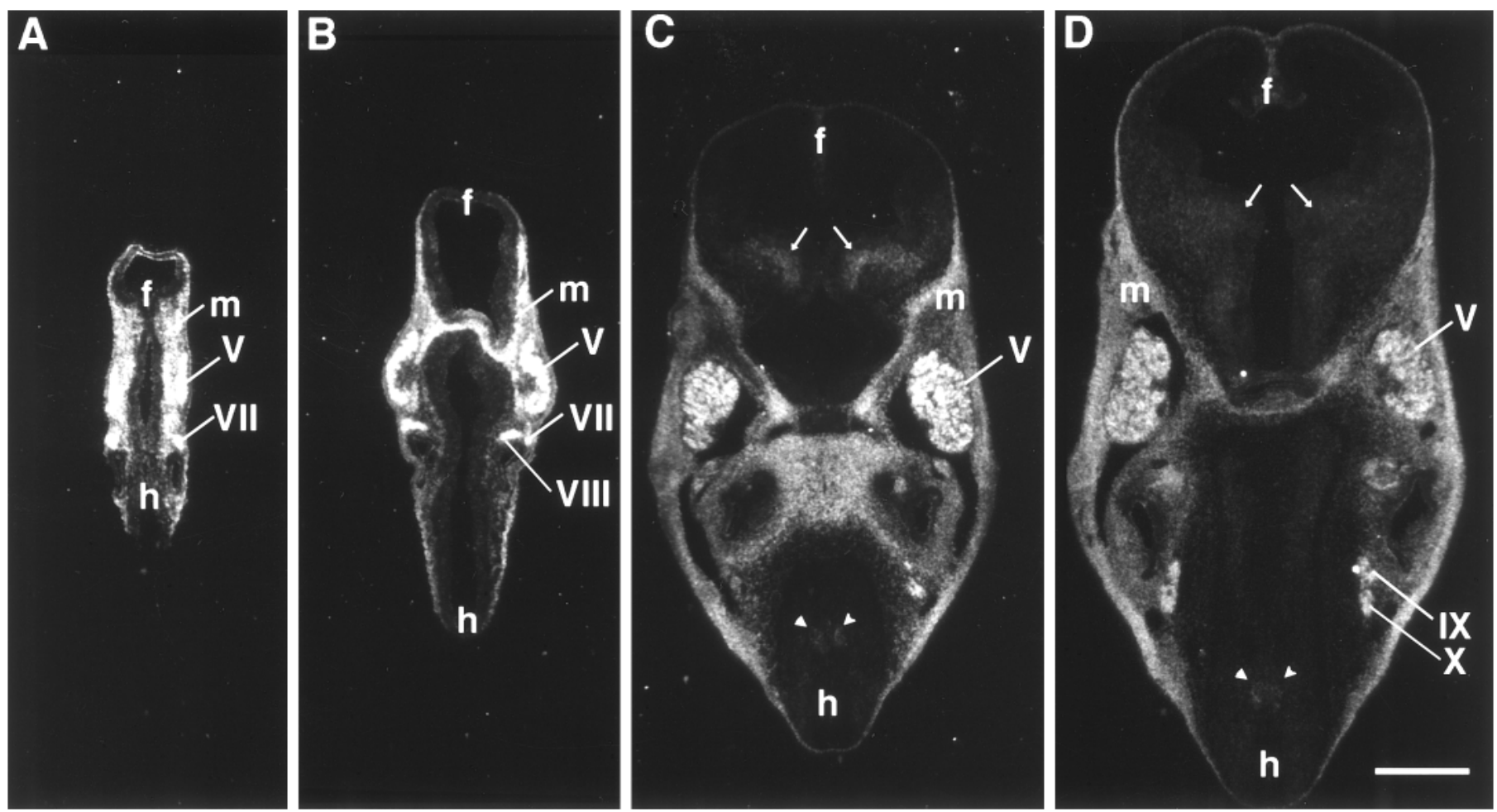

Figure 6. Expression of murine netrin-3 in the head region of the mouse embryo at E9.5 $(A)$, E10.5 $(B)$, E11.5 $(C)$, and E12.5 $(D)$. $V$, Trigeminal ganglion; VII, geniculate ganglion; VIII, vestibular ganglion; $I X$, glossopharyngeal ganglion; $f$, forebrain; $h$, hindbrain; $m$, mesenchyme. Arrows, Thalamus; arrowheads, positive signal in the ventral aspect of the neural tube in the hindbrain. Scale bar, $1.4 \mathrm{~mm}$.
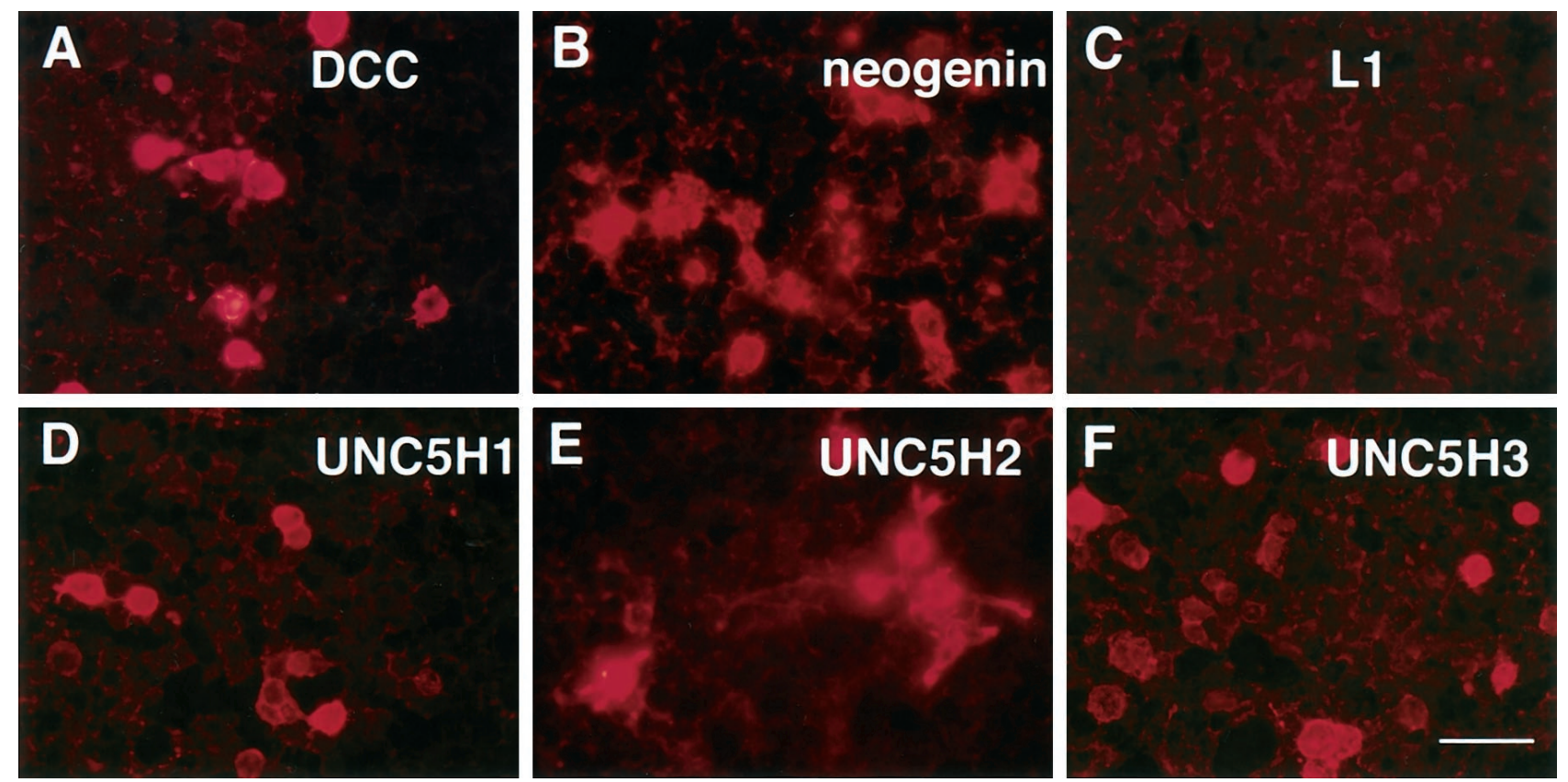

Figure 7. Murine netrin-3 protein binds to the netrin receptors DCC $(A)$, neogenin $(B), \mathrm{UNC} 5 \mathrm{H} 1(D)$, UNC5H2 $(E)$, and $\mathrm{UNC5H} 3(F)$ but not a control protein of the immunoglobulin gene superfamily, L1 $(C)$. Scale bar, $40 \mu \mathrm{m}$.

$(n>15)$ (Fig. 9C). However, the concentration of murine netrin-3 required to elicit optimal commissural axon outgrowth from E13 explants is $120 \mu \mathrm{g} / \mathrm{ml}$ (data not shown), approximately fourfold higher than that of netrin-1 (Kennedy et al., 1994), consistent with the lower apparent affinity of netrin-3(VI.V)-Fc for DCC.
We next examined whether netrin-3 also possesses chemorepulsive activity toward trochlear motor axons, an activity previously demonstrated for netrin-1 (Colamarino and Tessier-Lavigne, 1995). We therefore cocultured aggregates of transfected cells expressing netrin-3 with explants of ventral neural tube taken from the hindbrain-midbrain junction (HMJ) from E11 rats, which 


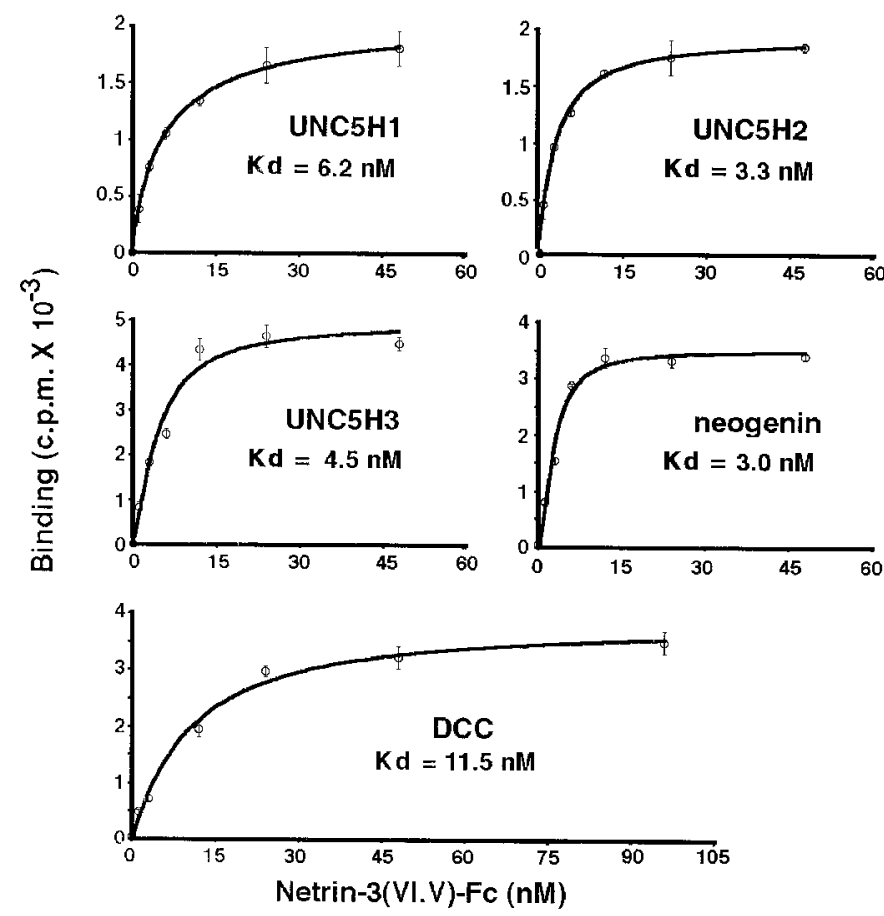

Figure 8. Equilibrium binding of the netrin-3(VI.V)-Fc fusion protein to UNC5H1, UNC5H2, UNC5H3, neogenin, and DCC. Binding of netrin3(VI.V)-Fc was determined by measuring the radioactivity associated with cells after subsequent incubation with radiolabeled anti-human IgG antibody. Specific binding curves were fitted using the Hill equation. $K_{\mathrm{d}}$ values for the interaction of netrin-3(VI.V)-Fc with UNC5H1, UNC5H2, $\mathrm{UNC5H3}$, neogenin, and $\mathrm{DCC}$ are 6.2, 3.3, 4.5, 3.0, and $11.5 \mathrm{~nm}$, respectively.

contain the cell bodies of trochlear motor neurons, as well as floor plate cells. In control cultures, trochlear motoneurons extend axons along a dorsally directed trajectory away from the floor plate within the explant. When they reach the cut edge of the explant, they project out into the collagen matrix and continue along their dorsal trajectory, unimpeded by control cells ( $n=9$ of 10 explants with a large axon bundle directed to the cells) (Fig. 9D) (Colamarino and Tessier-Lavigne, 1995). In contrast, when cultured with cells expressing netrin-3, the axons grew dorsally within the explant but, as they emerged into the collagen, they redirected their growth away from the exogenous source of netrin-3 ( $n=0$ of 10 explants with large bundles; two of these had short and splayed bundles, whereas the other eight had redirected their axons completely, as in Fig. $9 E$ ). These effects were similar to those observed with cells secreting netrin-1 (Colamarino and Tessier-Lavigne, 1995). Thus, netrin-3 also possesses chemorepulsive activity. Unfortunately, the qualitative nature of the assay did not make it possible to assess the specific activity of netrin-3 in repulsion.

\section{DISCUSSION}

We have described the cloning, expression, binding properties, and in vitro outgrowth-promoting activity of murine netrin-3. We found that this netrin gene is expressed in sensory ganglia, some CNS regions, mesenchymal tissues, and differentiating muscles. In addition, murine netrin- 3 binds to all the receptor molecules to which netrin-1 is known to bind and mimics the outgrowthpromoting activity of netrin-1 on spinal cord commissural neurons and its chemorepulsive activity on trochlear motor axons. However, unlike netrin-1, netrin-3 binds to these receptors dif- ferentially, showing lower affinity for DCC and, presumably as a consequence, lower specific activity than netrin- 1 in the commissural axon outgrowth assay (its specific activity in the chemorepulsive assay has not been assessed).

The high level of homology between murine netrin-3 and human NTN2L indicates that murine netrin-3 is likely to be the ortholog of human NTN2L. This conclusion is further supported by the fact that murine netrin-3 maps to a region of mouse chromosome 17 that is syntenic to the region of human chromosome $16 \mathrm{p} 13.3$ to which $N T N 2 L$ maps. In contrast, the lower homology between murine netrin-3 and chick netrin-2 suggests that murine netrin-3 may not be an ortholog of chick netrin-2. In agreement with this, we found that the expression pattern of murine netrin-3, especially during early stages of development, does not correspond to that of chick netrin-2. One important difference is that chick netrin-2 is expressed in the ventral twothirds of the spinal cord at approximately the time when commissural axons extend to the midline and has been suggested to form with netrin-1 (which is expressed in the floor plate), a gradient of netrin protein in the chick spinal cord (Kennedy et al., 1994). In contrast, in the mouse, netrin-3 is not expressed in the ventral spinal cord at early stages. Instead, murine netrin-1 alone is expressed both in the floor plate and the ventral two-thirds of the spinal cord (Serafini et al., 1996), suggesting that it may subserve the functions of both chick netrin-1 and chick netrin-2. Outside the spinal cord, the distribution pattern of murine netrin-3 is similar to that of chick netrin-2 in some respects but different in others. For example, both chick netrin-2 and murine netrin-3 are expressed in dorsal root ganglia; however, the onset of expression of chick netrin- 2 occurs at a later developmental stage than that of mouse netrin-3, which appears to be expressed as soon as neuronal differentiation commences in the ganglia. Similarly, murine netrin-3 is expressed as soon as neuronal differentiation starts in condensing cranial sensory ganglia, whereas no expression of chick netrin-2 was detected in cranial ganglia at comparable developmental stages (stages 16 to 26; data not shown). Other differences include the expression pattern in the dermomyotome and mesenchymal cells.

In addition to differences in sites of expression, a further apparent difference is that murine netrin-3 protein has a lower affinity for DCC than does netrin-1. Presumably as a consequence, murine netrin-3 has a lower specific activity in promoting commissural axon outgrowth in cell culture. It is difficult to make a precise comparison between affinities of chicken netrin-2 and mouse netrin-3 because the $K_{\mathrm{d}}$ for interaction of chick netrin-2 with DCC has not been measured. However, during the purification of the netrins from chick brain no striking difference in specific activity of the two chick proteins was observed (Serafini et al., 1994), suggesting that chick netrin-1 and netrin-2 likely have similar affinities for DCC and that chick netrin-2 may also bind DCC with higher affinity than does mouse netrin-3. Together, the differences in sequence, in expression pattern, and possibly in binding characteristics suggest that murine netrin-3 is neither the ortholog nor the functional homolog of chick netrin-2. It will be of interest to determine whether there is a mouse ortholog of chick netrin-2 and, conversely, whether there is a chick ortholog of mouse netrin-3.

Particularly striking sites of expression of murine netrin-3 are in sensory ganglia and, to a lesser extent, in the developing motor columns. Although we do not know whether it is expressed by neurons or by glia in the sensory ganglia and motor column, the onset of expression in the sensory ganglia correlates with the 

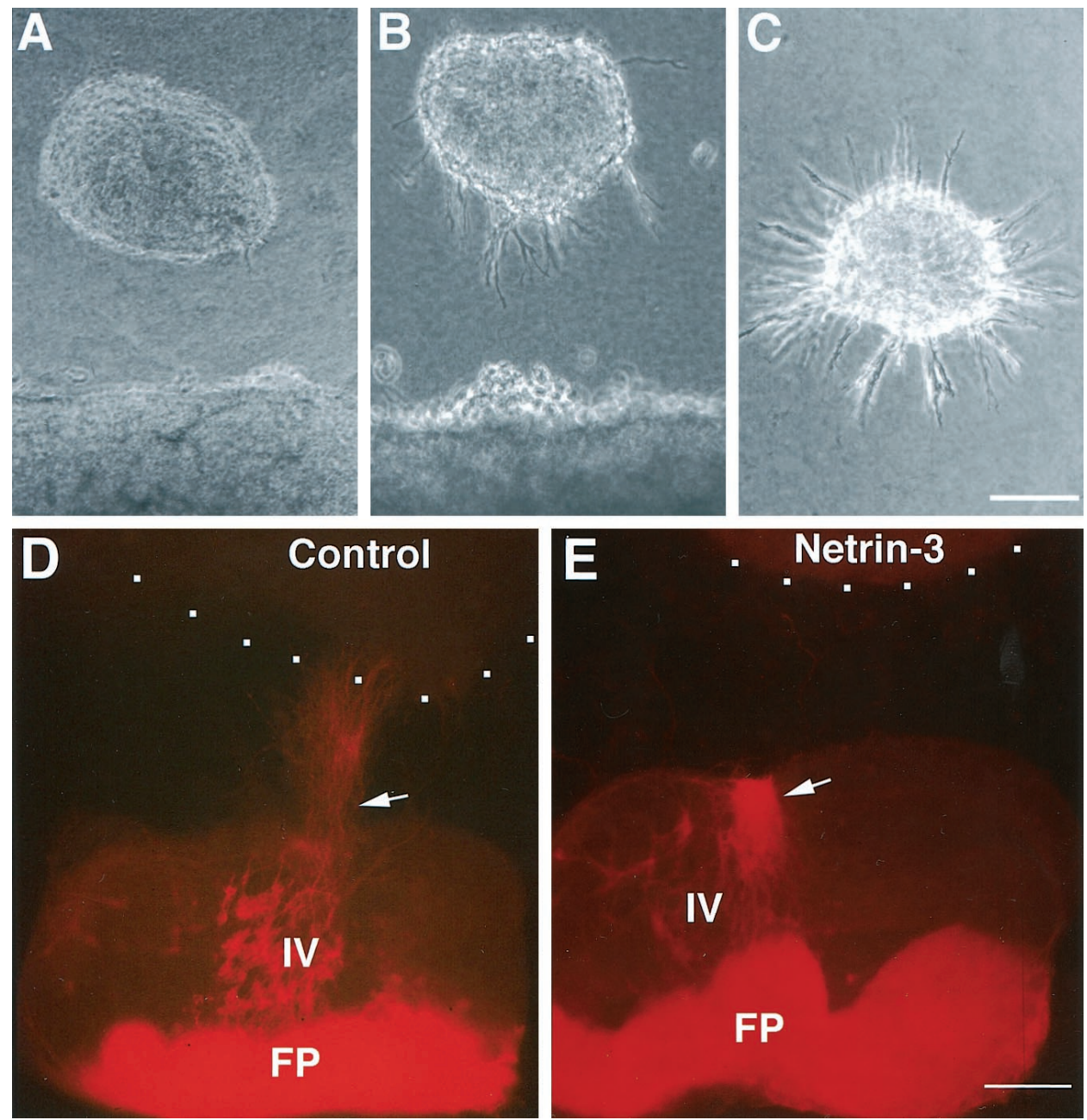

Figure 9. Outgrowth-promoting and chemorepulsive actions of netrin-3 in vitro. $A-C$, E13 dorsal spinal cord explants were cocultured with 293 EBNA cells mock-transfected with the vector pCEP4 $(A)$, with transfected 293 EBNA cells expressing netrin-3 $(B)$ or with purified netrin-3 protein $(120 \mu \mathrm{g} / \mathrm{ml})$ $(C)$. Netrin-3 promoted the outgrowth of spinal commissural axons from these explants. $D, E$, Explants of the ventral half of the HMJ of E11 rat embryos were cultured with 293 EBNA cells mock-transfected with the vector pCEP4 $(D)$ or with transfected 293 EBNA cells expressing netrin-3 $(E)$. Trochlear motor axons (arrows) originating from cell bodies in the trochlear nucleus $(I V)$ extended dorsally away from the floor plate $(F P)$ and into the collagen matrix. They continued to grow dorsally in the presence of control cells $(D)$ but were repelled by netrin-3-secreting cells $(E)$. In $D$ and $E$, dots show the outline of aggregates of transfected cells. Scale bar, $33 \mu \mathrm{m}$. onset of neuronal differentiation in these ganglia. If it is expressed by the neurons, it is possible that the neurons secrete netrin-3 and that secreted netrin-3 is displayed on axonal surfaces. It is known that the receptors neogenin, $\mathrm{UNC} 5 \mathrm{H} 1$, and $\mathrm{UNC} 5 \mathrm{H} 2$ are also expressed in the dorsal root ganglia and that DCC, neogenin, and UNC5H1 are expressed in the motor column (Keino-Masu et al., 1996; Leonardo et al., 1997). Netrin-3 protein produced by sensory neurons and motoneurons might therefore in principle bind to peripheral sensory and motor axons via these receptors. Indeed, in Drosophila, netrins are expressed in neurons throughout the CNS, and netrin protein can be detected immunohistochemically associated with axon tracts (Harris et al., 1996; Mitchell et al., 1996). Interestingly, in Drosophila mutants that carry a deletion of both netrin genes, occasional breaks in the longitudinal axon tracts are observed, suggesting that proper fasciculation may require netrin expression (Mitchell et al., 1996). Similarly, expression of UNC-6 in neurons in C. elegans is consistent with the hypothesis that netrin may produce some of its effects locally by being presented on axonal surfaces (Wadsworth et al., 1996). Thus, if netrin-3 is expressed on sensory axons in the mouse, it may regulate the fasciculation of axons or provide a guidance cue for later developing axons that encounter the axons of netrin-3expressing neurons.

In addition to its expression in sensory ganglia, murine netrin-3 is also expressed in a striking pattern in the differentiating muscles. Murine netrin-3 mRNA is first detected in myoblasts at low levels at approximately E10.5, and by E14.5, it is clearly expressed in the muscle cells. Interestingly, murine netrin-1 shows similar expression in muscles at E14.5, although a much higher level expression of murine netrin-1 is detected in the migrating myoblasts at E10.5 (Fig. 4). Although we do not know whether both genes are coexpressed in the same muscle cells at E14.5, the fact that they are both expressed in muscles suggests that mammalian netrin-1 and netrin-3 may both play a role in guiding peripheral axons to their correct muscle targets. A precedent for this is provided by the expression of netrin genes by subsets of muscle cells in Drosophila, and the demonstration that loss of netrin function, as well as ectopic expression of netrins in inappropriate muscles, can cause targeting defects for subsets of motor axons (Mitchell et al., 1996; Winberg et al., 1998). Whether netrins are required for peripheral motor axon guidance in mammals will require the examination of axon trajectories in mice lacking the function of netrin-1 and netrin-3.

In vitro murine netrin- 3 protein appears to bind all the receptor proteins to which netrin-1 binds and can mimic both the outgrowth-promoting activity of netrin- 1 on commissural axons and the chemorepulsive activity of netrin-1 on trochlear motor axons. The affinity with which netrin-3(VI.V)-Fc binds to neogenin, UNC5H1, UNC5H2, and UNC5H3 is comparable with that of netrin-1(VI.V)-Fc (Keino-Masu et al., 1996; Leonardo et al., 1997). However, the affinity of netrin-3(VI.V)-Fc for DCC is lower than for all other netrin receptors we tested and is approx- 
imately fourfold lower than that of netrin-1(VI.V)-Fc. It will therefore be of interest to determine whether netrin-3 in vivo is specialized for interactions with netrin receptors other than DCC and, in particular, for chemorepulsion. Examination of the lossof-function phenotype of netrin-3 mutant mice should help address this issue and determine its role in axon guidance and in the development of non-neural tissues.

\section{REFERENCES}

Ackerman SL, Kozak LP, Przyborski SA, Rund LA, Boyer BB, Knowles BB (1997) The mouse rostral cerebellar malformation gene encodes an UNC-5-like protein. Nature 386:838-842.

Chan SS, Zheng H, Su MW, Wilk R, Killeen MT, Hedgecock EM, Culotti JG (1996) UNC-40, a C. elegans homolog of DCC (deleted in colorectal cancer), is required in motile cells responding to UNC-6 netrin cues. Cell 87:187-195.

Chomczynski P, Sacchi N (1987) Single-step method of RNA isolation by acid guanidinium thiocyanate-phenochloroform extraction. Anal Biochem 162:156-159.

Colamarino SA, Tessier-Lavigne M (1995) The axonal chemoattractant netrin-1 is also a chemorepellent for trochlear motor axons. Cell 81:621-629.

Copeland NG, Jenkins N (1991) Development and applications of a molecular genetic linkage map of the mouse genome. Trends Genet 7:113-118.

Culotti J, Merz D (1998) DCC and netrins. Curr Opin Cell Biol 10:609-613.

de la Torre J, Hopker V, Ming G, Poo M, Tessier-Lavigne M, HemmatiBrivanlou A, Holt C (1997) Turning of retinal growth cones in a netrin-1 gradient mediated by the netrin receptor DCC. Neuron 19:1211-1224.

Fazeli A, Dickinson S, Hermiston M, Tighe R, Steen R, CG S, Stoeckli E, Keino-Masu K, Masu M, Rayburn H (1997) Phenotype of mice lacking functional deleted in colorectal cancer (DCC) gene. Nature 386:796-804.

Green MC (1989) Catalog of mutant genes and polymorphic loci. In: Genetic variants and strains of the laboratory mouse (Lyon MF, Searle AG, eds), pp 12-403. Oxford: Oxford UP.

Hamelin M, Zhou Y, Su MW, Scott IM, Culotti JG (1993) Expression of the UNC-5 guidance receptor in the touch neurons of $C$. elegans steers their axons dorsally. Nature 364:327-330.

Harlow E, Lane D (1988) Antibodies. Plainview, NY: Cold Spring Harbor Laboratory.

Harris R, Sabatelli L, Seeger M (1996) Guidance cues at the Drosophila CNS midline: identification and characterization of two Drosophila Netrin/UNC-6 homologs. Neuron 17:217-228.

Hedgecock EM, Culotti JG, Hall DH (1990) The unc-5, unc-6, and unc-40 genes guide circumferential migrations of pioneer axons and mesodermal cells on the epidermis in C. elegans. Neuron 4:61-85.

Ishii N, Wadsworth WG, Stern BD, Culotti JG, Hedgecock EM (1992) UNC-6, a laminin-related protein, guides cell and pioneer axon migrations in C. elegans. Neuron 9:873-881.

Jenkins NA, Copeland NG, Taylor BA, Lee BK (1982) Organization, distribution, and stability of endogenous ecotropic murine leukemia virus DNA sequences in chromosomes of Mus musculus. J Virol 43:26-36.
Keino-Masu K, Masu M, Hinck L, Leonardo ED, Chan SS, Culotti JG, Tessier-Lavigne M (1996) Deleted in colorectal cancer (DCC) encodes a netrin receptor. Cell 87:175-185.

Kennedy TE, Serafini T, de la Torre JR, Tessier-Lavigne M (1994) Netrins are diff usible chemotropic factors for commissural axons in the embryonic spinal cord. Cell 78:425-435.

Kolodziej PA, Timpe LC, Mitchell KJ, Fried SR, Goodman CS, Jan LY, Jan YN (1996) frazzled encodes a Drosophila member of the DCC immunoglobulin subfamily and is required for CNS and motor axon guidance. Cell 87:197-204.

Lauderdale J, Davis N, Kuwada J (1997) Axon tracts correlate with netrin-1a expression in the zebrafish embryo. Mol Cell Neurosci 9:293-313.

Leonardo ED, Hinck L, Masu M, Keino-Masu K, Ackerman SL, TessierLavigne M (1997) Vertebrate homologues of C. elegans UNC-5 are candidate netrin receptors. Nature 386:833-838.

Leung-Hagesteijn C, Spence AM, Stern BD, Zhou Y, Su MW, Hedgecock EM, Culotti JG (1992) UNC-5, a transmembrane protein with immunoglobulin and thrombospondin type 1 domains, guides cell and pioneer axon migrations in C. elegans. Cell 71:289-299.

Meyerhardt JA, Caca K, Eckstrand BC, Hu G, Lengauer C, Banavali S, Look AT, Fearon ER (1999) Netrin-1 interaction with deleted in colorectal cancer (DCC) and alterations in brain tumors and neuroblastomas. Cell Growth Differ 10:35-42.

Mitchell KJ, Doyle JL, Serafini T, Kennedy TE, Tessier-Lavigne M, Goodman CS, Dickson BJ (1996) Genetic analysis of Netrin genes in Drosophila: netrins guide CNS commissural axons and peripheral motor axons. Neuron 17:203-215.

Rooney RJ, Daniels R, Jenkins NA, Gilbert DJ, Rothammer K, Morris SW, Higgs DR, Copeland NG (1998) Chromosomal location and tissue expression of the gene encoding the adenovirus E1A-regulated transcription factor E4F in humans and mice. Mamm Genome 9:320-323.

Sambrook J, Fritsch EF, Maniatis T (1989) Molecular cloning, a laboratory manual. Plainview, NY: Cold Spring Harbor Laboratory.

Serafini T, Kennedy TE, Galko MJ, Mirzayan C, Jessell TM, TessierLavigne M (1994) The netrins define a family of axon outgrowthpromoting proteins homologous to C. elegans UNC-6. Cell 78:409-424.

Serafini T, Colamarino SA, Leonardo ED, Wang H, Beddington R, Skarnes WC, Tessier-Lavigne M (1996) Netrin-1 is required for commissural axon guidance in the developing vertebrate nervous system. Cell 87:1001-1014.

Strahle U, Fischer N, Blader P (1997) Expression and regulation of a netrin homologue in the zebrafish embryo. Mech Dev 62:147-160.

Tessier-Lavigne M, Goodman CS (1996) The molecular biology of axon guidance. Science 274:1123-1133.

van Raay TJ, Foskett SM, Connors TD, Klinger KW, Landes GM, Burn TC (1997) The NTN2L gene encoding a novel human netrin maps to the autosomal dominant polycyctic kidney disease region on chromosome 16p13.3. Genomics 41:279-282.

Wadsworth W, Bhatt H, Hedgecock E (1996) Neuroglia and pioneer neurons express UNC-6 to provide global and local netrin cues for guiding migrations in C. elegans. Neuron 16:35-46.

Wang H, Kunkel DD, Schwartzkrion PA, Tempel BL (1994) Localization of Kv1.1 and Kv1.2, two K channel proteins, to synaptic terminals, somata and dendrites in the mouse brain. J Neurosci 14:4588-4599.

Winberg M, Mitchell K, Goodman C (1998) Genetic analysis of the mechanisms controlling target selection: complementary and combinatorial functions of netrins, semaphorins, and IgCAMs. Cell 93: 581-591. 